\title{
50 ANOS DE A MULHER NA SOCIEDADE DE CLASSES: o pioneirismo de Heleieth Saffioti e suas contribuições teóricas para os estudos feministas e de gênero
}

\author{
Jules Falquet \\ Maíra Kubík Mano** \\ Renata Gonçalves ***
}

\section{INTRODUÇÃO}

Autora de múltiplas pesquisas sobre a "condição feminina" e, logo, sobre a situação das mulheres, Heleieth Saffioti transtornou, desde o início de sua carreira na década de 1960, o sisudo e masculino ambiente acadêmico. Com uma produção intelectual que ultrapassa o campo da Sociologia e se articula a importantes inserções práticas, tornou-se referência para os estudos feministas e de gênero, e reconhecida ativista nas lutas que a esse respeito se travaram no Brasil desde os anos de 1970. Um rápido exame da trajetória desta professora, pesquisadora, militante feminista e marxista revela extraordinário dinamismo e amplitude que se estendem das pesquisas em-

\footnotetext{
* Université de Paris. Centre d'Enseignement de Documentation et de Recherches pour les Etudes Féministes (CEDREF) Laboratoire du changement social et politique (LCSP).

5, rue Thomas Mann. 75013. Paris - França. jules.falquet@ univ-paris-diderot.fr

http//orcid.org/0000-0002-7502-2883

** Universidade Federal da Bahia. Núcleo de Estudos Interdisciplinares sobre a Mulher (NEIM).

Estrada de São Lázaro, 197 - Federação. Salvador - Bahia Brasil.maira.kubik@ufba.br https://orcid.org/0000-0002-4201-5636

*** Universidade Federal de São Paulo (campus Baixada Santista). Núcleo de Estudos Heleieth Saffioti (NEHS).

Rua Silva Jardim, 136. Santos - São Paulo - Brasil. renata. goncalves25@unifesp.br

https://orcid.org/0000-0002-2470-9095
}

píricas ao desenvolvimento de uma produção teórica de fôlego, além de encontros acadêmicos e presença em grandes momentos políticos relacionados com as organizações feministas e de mulheres dentro e fora do Brasil.

Resultado de uma tese de livre-docência defendida em 1967, A mulher na sociedade de classes: mito e realidade teve a primeira publicação dois anos depois. Passado meio século, esta obra permanece uma das principais referências para o feminismo. É o que explica a enorme acolhida da mais recente edição do livro que, trinta e quatro anos desde seu primeiro lançamento foi reeditado pela Expressão Popular. Além de prestar uma merecida femenagem à socióloga, a reedição também abriu "a possibilidade de que sua contribuição teórica continue a inspirar o pensamento crítico, sobretudo das novas gerações que, como Heleieth Saffioti, ousam com criatividade e muita luta soprar outros ventos de esperança na transformação social" (Gonçalves, 2013, p. 25).

Saffioti foi irreverente. Mesmo nos anos de ditadura militar, quando prevalecia o obscurantismo na vida social e política do país, com prisões arbitrárias, torturas, desapareci- 
mentos forçados e mortes, ela, mulher e professora, em uma região de mentalidade predominantemente provinciana e conservadora do interior do estado de São Paulo, ia à cadeia visitar presos políticos (Teles, 2011). De acordo com a entrevista concedida a Renata Gonçalves e Carolina Branco (2011, p. 78), nunca deixou de dizer o que pensava do regime militar, continuou a ministrar suas aulas sem recorrer a eufemismos. Esta é uma das razões pelas quais Heleieth faz falta nestes tempos de avanço de ideias autoritárias e de tentativa de cercear o pensamento crítico.

Na mesma entrevista, Saffioti também conta que o processo de elaboração do texto de livre-docência, entre o final de 1966 e o início de 1967, foi marcada por grandes dificuldades, a começar pelo deserto bibliográfico sobre o materialismo histórico-dialético, seu referencial teórico. Faltava-lhe a interlocução direta com autores/as que dariam sustentação a suas problematizações (Gonçalves, 2013, p. 13). Ser mulher num ambiente masculino e considerada comunista em pleno regime militar a tornou alvo de inúmeros boatos. Heleieth compreendeu que tinha de fazer uma tese porque, segundo ela, sendo mulher e marxista, a chance de a colocarem na rua era grande. Sobre ter de "parir uma tese", dizia: "os homens não precisam fazer e os não-marxistas tampouco, mas eu tenho que fazer!" (Gonçalves; Branco, 2011, p. 75).

A produção da tese foi tensa, porém nada \& se comparou ao assédio sofrido antes e durante ปे o momento da defesa. O próprio Conselho Estaผैं dual de Educação resolveu, segundo a socióloga, fazer uma guerra contra ela, que se materializou na troca de membros da banca às vésperas $\dot{2}$ do momento final. Houve intensa propaganda ळ gratuita, o que provocou a superlotação da sala $\therefore$ de defesa. Muita gente queria ver como a professora comunista se sairia na arguição. A atuação da banca apresentou elevado teor de misoginia e foi abertamente mais rigorosa com ela do que com seus competidores homens. Ainda assim, foi um sucesso. Os conhecimentos teóricos de Saffioti dissuadiram o membro da banca que, sob o aval do Conselho de Educação, estava lá para reprová-la com o argumento de que ela só tinha lido o Manifesto do Partido Comunista. Nada poderia ser tão enganoso. A escassez bibliográfica no Brasil não a impediu de ser criativa, nem de ler praticamente tudo que existia à época sobre seu tema de pesquisa. Recebeu a nota máxima pela tese.

A tese virou livro e a obra ganhou o mundo. Foi publicada pela primeira vez no Brasil em 1969, pela editora Quatro Artes. A editora Vozes encarregou-se das duas edições seguintes, em 1976 e 1979. Em nota acrescida à segunda, Saffioti observou que a literatura científica sobre seu tema de pesquisa crescera ao longo daquela década ao mesmo tempo em que também aumentaram os movimentos feministas: nos "Estados Unidos, na França, na Itália e em outros países, as mulheres movimentam-se visando a obter leis que lhes assegurem o controle de seu corpo e justiça na situação de trabalho e na sociedade em geral" (Saffioti, 1979, p. 7).

Foi nesse contexto de efervescência feminista que, em 1978, o livro foi traduzido para o inglês e publicado nos Estados Unidos pela Monthly Review Press. No prefácio a esta edição, Eleonor Burke Leacock (1978), apresenta Saffioti como uma mulher latino-americana, cuja análise se insere na perspectiva latino-americana. Observação arguta e pertinente se considerarmos que pululavam em solo estadunidense os estudos e mobilizações políticas que refutavam a ideia de mulher universal apresentada pelo feminismo hegemônico, o qual ignorou a existência de todas as mulheres não brancas (Hooks, 2015). Para Leacock, o livro não era apenas um ensaio teórico sobre a opressão das mulheres e a perpetuação das relações capitalistas em geral, mas lidava “com mulheres em um país, o Brasil, com um nível de detalhe histórico que é muito necessário para todas as áreas" (Leacock, 1978, p. ix). Escrever sobre a formação social brasileira significou lançar mão de um debate sobre os nexos da organização do trabalho feminino no 
interior das nações imperialistas e entre estas e sociedades dependentes ou subdesenvolvidas, conforme a nomenclatura utilizada por Saffioti, ou ainda terceiro-mundistas, como sugerido por Eleonor Burke Leacock.

A publicação em inglês abriu espaço para novos públicos e debates. Inúmeras resenhas foram feitas em muitos países e em várias línguas. Em uma delas, Ruby Rohrlich-Leavitt (1979) identificou na obra de Heleieth Saffioti a influência do trabalho de outras mulheres pioneiras, como Simone de Beauvoir, Betty Friedan e Juliet Mitchell. Na versão original (aquela da tese), constava apenas a referência à Simone de Beauvoir $^{1}$, utilizada com parcimônia porque Heleith nutria uma resistência emocional com o Segundo Sexo, que ela considerou "excessivamente culturalista”, envolvendo um conjunto de "crenças, normas, valores, mas não a praxis, fenômeno que, para ela, era "muito importante na construção de homens e mulheres e suas relações" (1999a, p. 162). Ao transformar a tese em livro, outras referências-chave para a temática foram incorporadas.

Uma faceta crucial que Rohrlich-Leavitt (1979) encontra na teoria de Saffioti é que o capitalismo recorre ao determinismo da biologia para marginalizar mulheres e grupos étnico-raciais no mercado de trabalho, criando uma força de trabalho que não pode ser regularmente absorvida.

A mulher na sociedade de classes já nasceu clássico e logo foi considerado o marco fundador para o campo dos estudos sobre a mulher no Brasil (Matos, 2013, p. 6). A importância do livro ficou mais evidente na passagem de seus 25 anos, quando foi tema de mesa redonda no Encontro Anual de Pós-Graduação e Pesquisa em Ciências Sociais (ANPOCS), um dos mais reconhecidos da área. Ali Bila Sorj (1995) ressaltou o pioneirismo da obra não apenas no Brasil, mas também internacionalmente, em especial no contexto dos debates sobre a relação entre mulheres e desenvolvi-

${ }^{1}$ Em entrevista, a socióloga enfatizou que não conhecia o livro de Betty Friedan (Gonçalves; Branco, 2011). mento, provocados pela publicação do Woman's Role in Economic Development, de Ester Boserup (1970). Esta argumentava que a marginalização das mulheres trabalhadoras era decorrência do processo de desenvolvimento em virtude de seus baixos ganhos econômicos. E preconizava que as "políticas de desenvolvimento deveriam se orientar a reparar este problema de tal forma que as mulheres pudessem participar de uma maneira mais plena dos frutos do desenvolvimento" (Sorj, 1995, p. 157).

Saffioti, ao contrário, destacava a incompatibilidade desta proposta com um projeto de sociedade em que perdura a propriedade privada dos meios de produção. A feminista brasileira podia até reconhecer certa maleabilidade no capitalismo, todavia isto não significa que este sistema possa oferecer uma integração social para todas as mulheres. O capitalismo "ora incorpora as mulheres ao sistema de produção, ora descarta-as e as marginaliza na família como exército de reserva, segundo as suas exigências para rebaixar os salários e dividir a classe trabalhadora mistificando, tanto para as mulheres quanto para os homens, a estrutura da exploração capitalista" (Sorj, 1995, p. 157). Segundo Heleieth Saffioti, o aparecimento do capitalismo se dá em condições extremamente adversas à força de trabalho feminina. A opressão das mulheres permite justamente que a sociedade capitalista arranque delas "o máximo de mais-valia absoluta, através, simultaneamente, da intensificação do trabalho, da extensão da jornada de trabalho e de salários mais baixos que os masculinos" (Saffioti, 1969, p. 40).

Hoje, 50 anos mais tarde, podemos enfatizar que, como previu Heleieth, o desenvolvimento do capitalismo, definitivamente, não representa avanço fundamental nas condições de vida das mulheres. E menos ainda quando se tratam de mulheres negras, que, em sua imensa maioria, continuam a ocupar os postos de trabalho mais precários. A estrutura racista do capitalismo brasileiro, para nos limitarmos a este caso, teima em empurrar estas mulhe- 
res para a invisibilidade das cozinhas ou dos novos porões do trabalho. Elas jamais deixaram a casa-grande, nunca se desvencilharam do emprego doméstico, uma extensão do trabalho escravo, mas foram lançadas em novas teias de precariedade, como as do trabalho de telemarketing. Além do trabalho doméstico informal, muitas mulheres foram "atraídas pelos novos postos formais de trabalho abertos no setor de serviços nos anos 2000, as filhas das empregadas domésticas entraram aos milhares na indústria do call center" (Braga, 2014, p. 34), sem que se assegure o acesso a direitos sociais que, em tese, não seriam incompatíveis com o capitalismo.

Em diálogo intenso com as teses contidas em A mulher na sociedade de classes, dois outros estudos de Heleieth Saffioti marcam essa primeira fase de sua produção intelectual voltada para as pesquisas sobre o trabalho feminino: um sobre o emprego doméstico (1978) e outro sobre as operárias têxteis (1981). Ambos demonstram como o capitalismo se alimenta da preservação tanto da organização arcaica de uma atividade, como é o caso do emprego doméstico, como da apropriação redefinida de atributos femininos na indústria e, neste sentido, impossibilita a emancipação feminina. Em Emprego doméstico e capitalismo, a autora observa que

[...]a modernização da economia, estando presentes fatores como alta concentração da renda nacional, baixo grau de escolarização das camadas mais pobres, industrialização intensiva de capital, não apenas traz benefícios materiais às mulheres, como também impele-as a aceitar, a fim de sobreviver, o desempenho de atividades mal remuneradas e pouco ou nada prestigiadas do ponto de vista social, sobretudo no chamado baixo terciário (Saffioti, 1978, p. 17-18).

No tocante à absorção de mão-de-obra feminina, as mulheres se deparam com vários problemas que vão da dupla jornada de trabalho à necessidade de qualificação, que em geral era oferecida por homens e aos homens, levando a uma segregação ocupacional.
De acordo com Heleieth, “à medida que a máquina vai sendo absorvida pela indústria, as mulheres vão cedendo lugar aos homens" (Saffioti, 1981, p. 176), mesmo nos espaços reconhecidos como tradicionalmente "femininos", como no caso da indústria têxtil.

Ao longo dos anos 1980, uma de suas preocupações, ainda bastante ligada às pesquisas acima referidas, foi a investigação sobre a força de trabalho feminina no capitalismo agrário. Em Famílias rurais no estado de São Paulo, texto escrito em coautoria com Vera Lúcia Botta Ferrante, observam-se as enormes dificuldades com as quais as trabalhadoras do meio rural têm de lidar num contexto de proletarização precária, que retira delas a possibilidade de desempenharem um relevante papel econômico. Neste processo, o trabalho, antes em conjunto, se individualiza e o assalariamento "não tem as mesmas consequências para o homem e para a mulher" (Saffioti; Ferrante, 1982, p.117). Num passado recente, eram as mulheres as responsáveis pela produção da subsistência da família como uma extensão de suas tarefas domésticas. Com o processo de individualização do trabalho sob o capitalismo, parcela significativa de mulheres é excluída das funções econômicas, "sendo a elas atribuídas unicamente as tarefas domésticas” (Saffioti; Ferrante, 1982, p.130).

A dramática condição social das populações rurais num momento histórico de intensificação da acumulação capitalista no campo foi por ela retratada nos prefácios de dois dos livros fundamentais sobre o processo de proletarização dos trabalhadores agrícolas no Brasil, agravado pelas circunstâncias históricas de ocupar a periferia do sistema capitalista internacional. O primeiro trata-se de Boia-fria - acumulação e miséria, de Maria da Conceição D’Incao e Mello (1976), que faz uma análise da acumulação capitalista no campo, que gerou a figura do trabalhador não-qualificado instável. Este para sobreviver passou a perambular entre campo e cidade em busca de trabalho no baixo terciário ou, como diarista das 
plantações de cana, nas fazendas de produção mercantil (Saffioti, 1976, p. 8).

O segundo é quase uma extensão do anterior: Errantes do fim do século, de Maria Aparecida de Moraes Silva, que a apresenta as filigranas da violência imposta a trabalhadores/ as do campo, com desapropriações, desenraizamentos, grilagens, assassinatos; além dos controles sociais dos/as trabalhadores/as por meio de listas com nomes de "sindicalistas", com pesagem fraudulenta da cana, com ameaças de desemprego. Situações que levam estes/as a degradarem-se física, psíquica e moralmente, dados os constrangimentos de toda ordem a que são submetidos/as (Saffioti, 1999b, p. 8). Errantes tem o mérito de utilizar uma das categorias que Heleieth começava a conceituar: o nó das contradições de gênero, raça/etnia e classe, em especial no capítulo intitulado "Mulher, negra, 'boia-fria' a três vozes”, em que entrevista três trabalhadoras negras cujas vidas foram atravessadas pela articulação entre violência patriarcal, racismo e capitalismo. Tratam-se de três mulheres que sempre trabalharam, tiveram filhos, foram abandonadas pelos maridos/companheiros e vivenciaram relações de violência de gênero, de raça/etnia. Assim, Cida, uma das entrevistadas, revela que apanhava do pai e dos irmãos, mesmo cuidando dos afazeres domésticos quando criança. Quando se tornou adolescente desempenhou várias funções no trabalho rural: arrancou amendoim, cortou cana, apanhou algodão, foi empregada doméstica, mas "em todos estes trabalhos, nunca sequer foi registrada, portanto, nunca obteve qualquer direito trabalhista" (Silva, 1999, p. 271). Uma situação que se estende aos dias atuais, quando mulheres negras foram resgatadas em casas de famílias da alta classe média trabalhando em condições análogas à escravidão, sem remuneração e morando nos mofados, fétidos e escuros quartinhos de empregada, a nova versão das senzalas no Brasil.

Dos anos de 1990 a boa parte dos anos 2000, Heleieth Saffioti investigou as contribuições feministas para os estudos das imbri- cações entre gênero e violência. São vários os artigos assinados por ela sobre violência sexual, violência conjugal, violência doméstica, violência contra a mulher, violência estrutural e, por fim, violência de gênero. O último conceito é bem mais amplo e parece abranger as formulações anteriores acerca das várias vítimas (Saffioti, 2001).

Segundo a autora, no exercício da função patriarcal, os homens "detêm o poder de determinar a conduta das categorias sociais nomeadas, recebendo autorização ou, pelo menos, tolerância da sociedade para punir o que se lhes apresenta como desvio" (Saffioti, 2001, p. 115). O que está em jogo é a manutenção do projeto de dominação-exploração da categoria social homens, cuja capacidade de mando é auxiliada pela violência. Para ela, a "ideologia de gênero é insuficiente para garantir a obediência das vítimas potenciais aos ditames do patriarca, tendo este, necessidade de fazer uso da violência” (Saffioti, 2001, p. 115). Este poder masculino extrapola as relações do âmbito doméstico e se ramifica nas demais instituições.

Suas pesquisas empíricas e formulações teóricas levaram nossa autora a compreender a violência como uma relação social, impossibilitando reduzir um indivíduo a mero objeto ou a um sujeito passivo (Saffioti, 1997). Embora a violência de gênero esteja em todos os poros de nossa sociedade, é importante perceber que os mecanismos de resistência estão sempre presentes, alcançando maior ou menor êxito. Isto significa que as mulheres sempre reagem contra o agressor das mais variadas maneiras e "suas reações podem não ser adequadas para pôr fim à violência de seus parceiros, mas, é importante frisar, existem, se não em todos os casos, pelo menos na maioria esmagadora deles" (Saffioti, 2001, p. 121).

Apesar de não ser possível fazer uma separação nítida entre os temas da produção teórica de Heleieth Saffioti, percebe-se que ao longo do decênio que antecedeu o ano de sua morte, suas investigações se voltaram com maior densidade para o debate, jamais encer- 
rado, sobre os nexos entre capitalismo, patriarcado e racismo. Recorrendo a outras feministas, nossa autora define o patriarcado como um pacto masculino para garantir a opressão de mulheres. Saffioti destaca que a base material do patriarcado nunca foi destruída e, sob este regime, "as mulheres são objetos da satisfação sexual dos homens, reprodutoras de herdeiros, de força de trabalho e de novas reprodutoras" (Saffioti, 2004, p. 105). Na contramão das autoras que abandonaram o conceito de patriarcado para recorrer ao conceito de gênero, Heleieth observa que é preciso utilizar gênero e patriarcado de forma imbricada e, "ao invés de abandonar a ideia do patriarcado”, é preciso "questionar a sua validade universal e delimitar seus limites e fronteiras históricas" (Motta, 2018, p. 155).

Heleieth Saffioti partiu em 14 de dezembro de 2010 e nos deixou uma vasta produção intelectual. De A mulher na sociedade de classes ao seu último livro, Gênero, patriarcado, violência, ela colaborou enormemente para a consolidação dos estudos feministas e de gênero. O dossiê aqui apresentado busca retomar suas contribuições teóricas nas diversas áreas do conhecimento pelas quais transitou. Os artigos aqui reunidos apresentam temáticas abordadas por Saffioti, nas quais se destacam os estudos de gênero; o debate acerca do conceito de patriarcado; as relações desiguais de trabalho; as pesquisas sobre a violência contra a mulher; a จ elaboração de políticas públicas; a presença de ฟิ suas teorias em movimentos sociais; a análise ผิ้ da articulação de gênero, raça e classe etc.

No primeiro artigo do dossiê, Céli Regina Pinto nos lembra que a importância do . trabalho de Saffioti está em reconhecer uma condição própria das mulheres na estrutura de classes: "Não foi tarefa fácil para uma acadêmica marxista, na década de 1960, tratar de um agente social - as mulheres - que não tinha lugar no construto teórico", afirma. Para refletir sobre esta contribuição, Céli Pinto aborda dois momentos específicos: o início dos anos de 1980, quando houve uma produção muito qualificada, que discutiu a relação entre feminismo e marxismo; e o momento atual, fim da segunda década do século 21, quando o capitalismo tem provocado fortes ataques às conquistas das mulheres.

Daniele Motta, no segundo texto, defende que Heleieth Saffioti deveria compor o rol de pensadores sociais brasileiros, pois sua obra traz uma interpretação inovadora e original ao colocar em evidência o fato de que transitamos para o moderno, o modo capitalista de produção, sem romper com o tradicional, representado pelas relações patriarcais. "Dessa forma", ressalta Daniele Motta, "a autora nos leva a crer que a análise das relações entre homens e mulheres é parte fundamental para compreensão do autoritarismo no país”. Mas, como pioneira na temática sobre as mulheres, muitas vezes a Sociologia feita por Saffioti foi considerada "menor" e "menos importante para tratar dos 'grandes dilemas da sociedade”."

O terceiro artigo que integra o dossiê, escrito por Tita Carneiro e Maíra Kubík Mano, retoma a perspectiva da práxis, que esteve presente durante toda a obra de Saffioti, para refletir sobre suas contribuições para os pensamentos e as lutas feministas no Brasil. As autoras ressaltam a importância que Saffioti atribuía a uma ciência emancipatória e a complexidade de suas análises: a opção pelo materialismo histórico-dialético faz com que, no esforço de compreensão da realidade pesquisasse detalhadamente teorias fundamentadas em outras matrizes, às vezes para melhor criticá-las e, em tantas outras, com vistas à incorporação crítica de conceitos não necessariamente vinculados à perspectiva da qual foi defensora até o final de sua vida.

Elaine Bezerra, Roseli de Fátima Corteletti e Iara Maria de Araújo, no quarto artigo, assumem como aporte teórico os pressupostos da sociologia do trabalho e gênero e, de forma especial, a matriz teórica desenvolvida por Saffioti para pensar as transformações atuais no mundo do trabalho e as desigualdades dele decorrentes. Duas realidades específicas, marcadas pela flexibilidade e precariedade 
do trabalho e com força de trabalho intensiva de mulheres na região nordeste do Brasil, são analisadas: a primeira, a de mulheres costureiras/proprietárias de pequenas facções de costura, que trabalham em seus domicílios como terceirizadas para facções maiores, fabricos ou empresas situadas no Polo de Confecções do Agreste de Pernambuco; a segunda, da experiência têxtil vivenciada no município de Jardim de Piranhas, localizado no sertão do Seridó, no estado do Rio grande do Norte, onde a especialidade é a produção de redes de dormir, cobertores, toalhas e panos de prato.

A partir de uma reflexão bastante atual sobre os impactos da COVID-19 na vida das mulheres negras, Claudia Mazzei Nogueira e Raquel Gouveia Passos, com um olhar para o mercado de trabalho brasileiro e dando ênfase ao trabalho doméstico e de cuidados, indagam sobre quem dispõe do "privilégio da servidão". As autoras dialogam com Saffioti sobre a divisão sociossexual e racial do trabalho e suas expressões na sociedade contemporânea, percebendo como há uma hierarquia na distribuição dos poderes e dos acessos entre as próprias mulheres.

Por fim, Daniele Motta e Raquel Lindôso entrevistam a pesquisadora e educadora feminista Betânia Ávila, da organização SOS Corpo - Instituto Feminista para a Democracia, que rememora sua trajetória, o exílio na França e a importância de Saffioti para a teorização feminista. Segundo a entrevistada, Saffioti, a quem sempre chama de Heleieth, estabeleceu, desde os anos 1980, um intenso e permanente diálogo com o movimento feminista e com sua elaboração teórica, construindo uma "triangulação muito importante entre luta feminista, universidade e organizações feministas".

Nossa femenageada manteve-se intelectualmente inquieta até o fim de sua vida. Seu último artigo publicado em vida, "Quantos sexos? Quantos gêneros? Unissexo/Unigênero?, foi impresso em 2009 nos Cadernos de Crítica Feminista, revista do SOS Corpo - Instituto Feminista para a Democracia. O texto retoma parte de sua trajetória acadêmica e de suas contribuições teóricas para analisar a crise do período que, como previu, empurrou as mulheres para a informalidade. Mas o que é novo nesse artigo é o esforço de Saffioti para se manter atualizada no debate em torno da identidade de gênero e da orientação sexual. Quantos sexos? Quantos gêneros? Cabe pensar, escreve a socióloga

os sexos como anônimos e a sexualidade como uma potencialidade originária difusa, pousando ora num, ora noutro objeto de desejo, sem fixidez a que obriga o dualismo. A multiplicidade de afetos, num registro não patriarca, num registro não fálico, pode sim se traduzir em desejos móveis, não fixos (Saffioti, 2009, p. 24).

Sem dúvida, as formulações de Heleieth Saffioti seguem contribuindo para uma teoria social que, em sua perspectiva, tem como desafio a construção de uma agenda teórica e política que seja ao mesmo tempo antipatriarcal, antirracista e anticapitalista. É por isso que sua obra é tão urgente e atual.

Recebido para publicação em 20 de julho de 2020 Aceito em 05 de outubro de 2020

\section{REFERÊNCIAS}

BOSERUP, Ester. Woman's Role in Economic Development. Londres: Earthscan, 1970.

BRAGA, Ruy. Precariado e sindicalismo no Brasil contemporâneo: um olhar a partir da indústria do call center. Revista Crítica de Ciências Sociais, Lisboa, n. 103, p. 25-52, 2014.

DINCAO e MELLO, Maria da Conceição. O bóia-fria acumulação e miséria. Petrópolis: Editora Vozes, 1976.

GONÇALVES, R.; BRANCO, C. Entrevista - Heleieth Saffioti por ela mesma: antecedentes de "A mulher na sociedade de classes". Lutas Sociais, São Paulo, n. 27, 2011.

GONCALVES, R. O pioneirismo de A mulher na sociedade de classes. In: SAFFIOTI, H. A mulher na sociedade de classes: mito e realidade. São Paulo: Expressão Popular, p. 11-25, 2013.

HOOKS, Bell. Mulheres negras: moldando a teoria feminista. Revista Brasileira de Ciência Política, Brasília, n. 16, Brasília, p. 193-210, 2015.

LEACOCK, E. B. Introduction. In: SAFFIOTI, H. Women in Class Society. New York; London: Monthly Review Press, p. ix-xxiv, 1978, p. ix-xxiv.

ROHRLICH-LEAVITT, Ruby. H.I.B. Saffioti, Women in Class Society. Paris: L'Homme, 1979, tome $19 \mathrm{n}^{\circ} 3-4$. Les catégories de sexe en anthropologie sociale. p. 244-245. 
MATOS, M. I. História das mulheres e das relações de gênero: campo historiográfico, trajetórias e perspectiva. Mandrágora, São Paulo, v.19, n. 19, p. 5-15, 2013.

MOTTA, D. C. Desvendando Heleieth Saffioti. Lutas Sociais, São Paulo, São Paulo, v. 22 n.40, p.149-160, 2018.

SAFFIOTI, H. A mulher na sociedade de classes: mito e realidade. São Paulo: Quatro Artes, 1969.

Prefácio. In: MELLO, M.C.I. Boia-fria: acumulação e miséria. Petrópolis: Vozes, 1976. Vozes, 1978 Emprego doméstico e capitalismo. Petrópolis:

A mulher na sociedade de classes: mito e realidade. Petrópolis: Vozes, 1979.

Do artesanal ao industrial: a exploração da mulher. São Paulo: Hucitec, 1981.

Violência de gênero: o lugar da práxis na construção da subjetividade. Lutas Sociais, São Paulo, n. 2, p. 59-79, 1997.

Prefácio. In: SILVA, M. A. M. Errantes do fim do século. São Paulo: Unesp, 1999a.

Primórdios do conceito de gênero. Cadernos Pagu, Campinas, n. 12, p. 157-163, 1999 b.
Contribuições feministas para o estudo da violência de gênero. Cadernos Pagu, Campinas, n. 16, p. 115-136, 2001.

Gênero, patriarcado e violência. São Paulo: Fundação Perseu Abramo, 2004.

Quantos sexos? Quantos gêneros? Unissexo/ Unigênero? Cadernos de Crítica Feminista, Recife, n. 2, p. 06-32, 2009.

; FERRANTE, V.L.B. Famílias rurais no estado de São Paulo: algumas dimensões da vida feminina. In: BRUSCHINI, M. C.; ROSEMBERG, F. (orgs.). Trabalhadoras do Brasil. São Paulo: Brasiliense, 1982.

SILVA, M. A. M. Errantes do fim do século. São Paulo: Unesp, 1999.

SORJ, B. Dois olhares sobre Heleieth Saffioti: o feminismo adentra a academia. Revista Estudos Feministas, Rio de Janeiro, n. 1, p. 156-158, 1995.

TELES, Maria Amélia de Almeida. Heleieth, a ousadia do livre pensar feminista! Caros Amigos, Edição especial. São Paulo. Disponível em: <http:// carosamigos.terra. com.br/index/index.php/artigos-e-debates/1297-heleietha-ousadia-do-livre-pensar-feminista->. Acesso em 15 de julho de 2011.

Jules Falquet - Doutora em Sociologia pelo Institut des Hautes Etudes de l'Amérique latine (IHEAL), Université Sorbonne Nouvelle. É docente da Université de Paris; Centre d'Enseignement, de Documentation et de Recherches pour les Études Féministes (CEDREF), Laboratoire du changement social et politique (LCSP). Desenvolve pesquisas sobre as seguintes temáticas: movimentos sociais latino-americanos e caribenhos frente à globalização neoliberal, imbricação das relações de poder de sexo, raça e classe, epistemologia, violência, militarismo, migrações, ecofeminismo. Publicações recentes: Imbrication. Femmes, race et classe dans les mouvements sociaux. Paris: Le Croquant. 302 p. 2020; Hommage à Colette Guillaumin (com Maira Abreu et Dominique Fougeyrollas), Cahiers du Genre, 2020; Epistémologies féministes décoloniales. Controverses et dialogues transatlantiques, (com Artemisa Flores Espínola), Cahiers du CEDREF, n²3, 204p. 2019; Pax Neoliberalia. Perspectivas feministas sobre (la reorganización de) la violencia. Buenos Aires: Madreselva, 155p. 2017.

Maíra Kubík Mano - Doutora em Ciências Sociais pela Universidade Estadual de Campinas. Docente do Departamento de Estudos de Gênero e Feminismo da Universidade Federal da Bahia e do Programa de Pós-Graduação em Estudos Interdisciplinares sobre a Mulher (PPGNEIM). Pesquisadora do Núcleo de Estudos Interdisciplinares sobre a Mulher (NEIM). Atualmente se dedica a pesquisar os retrocessos em relação aos direitos das mulheres em um contexto de ataque às pautas de gênero e diversidade; e também à representação política e atuação das mulheres eleitas no Parlamento brasileiro. Publicações recentes: Atuar como mulheres - um olhar sobre a política institucional (Curitiba: Appris, 2020). As mulheres desiludidas: de Simone de Beauvoir à ideologia de gênero. Cadernos Pagu, v. 56, p. 1-25, 2019; Fascismo social e pautas feministas: construindo parâmetros para a intensidade da democracia brasileira. In: Danusa Marques; Daniela Rezende; Maíra Kubík Mano; Rayza Sarmento; Viviane Gonçalves Freitas. (Org.). Feminismos em rede. 1ed. 2019, p. 15-28; Direitos reprodutivos: um dos campos de batalha do Golpe. Em co-autoria com Márcia Macedo. In: Linda Rubim; Fernanda Argolo. (Org.). O Golpe na perspectiva de gênero. 1ed.: EDUFBA, 2018, p. 85-103.

Renata Gonçalves - Doutora em Ciências Sociais pela Universidade Estadual de Campinas. Docente da Universidade Federal de São Paulo, campus Baixada Santista; coordenadora do Núcleo de Estudos Heleieth Saffioti (NEHS) e do Núcleo de Estudos Reflexos de Palmares: análise da questão racial no Brasil. É vice-coordenadora do Núcleo de Estudos Afro-Brasileiros (NEAB) da Unifesp. Atualmente, se dedica a pesquisar as classes sociais em sua imbricação com as relações de gênero e raça; feminismo negro; racismo no Brasil e movimentos sociais. Publicações recentes: Lélia Gonzalez: uma rosa negra para novas primaveras! Resenha de 'Lélia Gonzalez: primavera para as rosas negras'. Revista Plural. São Paulo, v. 26, n. 1, p. 193-196, 2019; A invisibilidade das mulheres negras no ensino superior. POIÉSIS - Revista do Programa de Pós-Graduação em Educação (Unisul). Tubarão-SC, v. 12, n. 2, p. 350-367, 2018; Do Plano Nacional de Políticas para as Mulheres ao "machistério de Temer. Revista de Políticas Públicas (UFMA), São Luís, v. 22, n. 2, p. 753-771, 2018 (co-autoria Suellen Abreu). Páginas feministas de Outubro. Ponto-e-Vírgula, São Paulo, v. 21, p. 21-35, 2017. 